\title{
Burnout Syndrome: an analysis of the mental health of medical residents in a teaching hospital
}

Síndrome de Burnout: uma análise da saúde mental dos residentes médicos de um Hospital Escola

\author{
José Augusto Costa' (1) drcosta@globo.com \\ Nicoli Abrão Fasanella' (1) nicoliabrao@gmail.com \\ Beatriz Mendonça Schmitz' (1) biaschmitz03@gmail.com \\ Patrick Cavalcanti Siqueira' (1) $\mid$ siqueirap519@gmail.com
}

\begin{abstract}
Introduction: Medical residency can cause burnout syndrome, a physical, emotional and mental state of extreme exhaustion.

Objective: This research sought to describe and analyze the prevalence of burnout in resident physicians linked to a teaching Hospital and to verify whether there is a correlation with sociodemographic and socioeconomic data.

Method: This is an analytical, cross-sectional and quantitative study using the MBI (Malasch Burnout Inventory) version HSS (Human Services Survey), the Brazilian Economic Classification Criterion (CCEB) of ABEP and sociodemographic questions.

Result: Of the enrolled residents, 102 participated in the survey. Of these, 76.47\% showed a high level in at least one of the three domains of the burnout index and $21.57 \%$ of the residents showed a high level of burnout. There was a significant relationship between a larger number of children and the presence of emotional exhaustion $(P=0.047)$, a higher frequency of depersonalization for surgical area residents $(P=0.013)$ and reduced professional accomplishment, with an average income of $R \$ 2,965.69$ and $R \$ 10,386.52(P=0.006)$. No significant relationship was found between burnout and sociodemographic and socioeconomic variables.
\end{abstract}

Conclusion: The results show that resident physicians are exposed to situations that contribute to high levels of stress and distress. Further studies on the subject are still necessary.

Keywords: Burnout; Professional; Medical Staff Hospital; Resident Physicians; Depression.

\section{RESUMO}

Introdução: A residência médica pode causar a síndrome de burnout, um estado físico, emocional e mental de exaustão extrema.

Objetivo: Buscou-se com esta pesquisa descrever e analisar a prevalência de burnout em médicos residentes vinculados a um hospital-escola e verificar se há correlação com dados sociodemográficos e socioeconômicos.

Método: Este é um estudo analítico, transversal e quantitativo realizado por meio do Maslach Burnout Inventory (MBI) versão Human Services Survey (HSS), do Critério de Classificação Econômica Brasil (CCEB) da Abep e de perguntas sociodemográficas.

Resultado: Dos 221 residentes matriculados, 102 participaram da pesquisa. Destes, 76,47\% apresentaram alto nível em pelo menos um dos três domínios do índice de burnout e $21,57 \%$ dos residentes exibiram alto nível de burnout. Houve relação significativa entre maior número de filhos e presença de exaustão emocional $(p=0,047)$, maior frequência de despersonalização para residentes da área cirúrgica $(p=0,013)$ e reduzida realização profissional com a renda média de $R \$ 2.965,69$ e $R \$ 10.386,52(p=0,006)$. Não foi encontrada relação significativa entre burnout e as variáveis sociodemográficas e socioeconômicas.

Conclusão: Os resultados evidenciam que os médicos residentes estão expostos a situações que contribuem para os altos níveis de estresse e angústia. Ainda são necessários mais estudos sobre o tema.

Palavras-chave: Burnout; Esgotamento Profissional; Corpo Clínico Hospitalar; Médicos Residentes; Depressão.

${ }^{1}$ Pontifícia Universidade Católica de São Paulo, São Paulo, São Paulo, Brazil.

Chief Editor: Rosiane Viana Zuza Diniz.

Associate Editor: Rosiane Viana Zuza Diniz.

Received on 07/05/21; Accepted on 11/09/21.

Evaluated by double blind review process. 


\section{INTRODUCTION}

Burnout is a word of the English language that can be understood as "to burn until the fuel is exhausted"1. Currently, it is used to designate a process of psychosocial suffering arising from the work situation, since the work environment and its organization can be responsible for the feeling of physical and emotional exhaustion, which causes dissatisfaction with work².

There are several definitions of Burnout in the literature. For Maslach and Jackson, renowned authors on this subject, "Burnout is a syndrome of emotional exhaustion, depersonalization and reduced professional accomplishment, which can occur among individuals who work with people" ${ }^{\prime \prime}$. According to renowned American researcher Christina Maslach, Burnout is characterized by 3 dimensions: Emotional exhaustion (EE); Depersonalization (DE); and reduced professional accomplishment $(\mathrm{PA})^{4}$. Emotional exhaustion occurs when the professional has feelings of exhaustion or lack of energy; depersonalization happens in response to exhaustion, increasing the employee's mental distance or the feeling of negativity or cynicism related to someone's work; the reduced professional accomplishment manifests due to the lack of personal and/or organizational resources that interfere in the reduction of professional effectiveness ${ }^{2}$.

Given its relevance, studies on the topic of burnout in resident physicians have been developed in recent years, emphasizing the need to increase knowledge on the topic, seeking to identify predisposing factors, risks and, mainly, to propose changes for its prevention .

Currently, medical residency is considered the most physically and emotionally exhausting part of the physician's professional specialization process ${ }^{5}$. This is due, on the one hand, to the high educational requirements and, on the other hand, to the demands of the work environment with excessive demands that reduce the quality of care, long working hours, many days and nights on duty, low pay, need to deal with suffering and death, constant exposure to risk, lack of reciprocity in professional relationships and uncertainty about the future ${ }^{6}$. Therefore, the presence of stressors that lead to the appearance of burnout is well-known?

For comparison purposes, a longitudinal study carried out with 422 American physicians showed that $27 \%$ had symptoms of burnout ${ }^{8}$. In another study, it was found that more than half of practicing American physicians are affected by burnout ${ }^{2}$. In China, a cross-sectional study involving 1,537 physicians showed that $76.9 \%$ of the respondents reported some symptom and $54.8 \%$ reported having made some type of medical error over the past year 9 .

When observing the Brazilian situation, it is already known that health professionals, together with teachers, are the most investigated categories, precisely because of the alarming data from these studies ${ }^{2}$. Despite this, there is still little information about burnout in Brazil' ${ }^{2}$. In the state of Rio Grande do Norte, a study carried out with professionals from three hospitals found that $93 \%$ of professionals from one of these hospitals had burnout ${ }^{10}$. While another study carried out in a Public Hospital in the west zone of São Paulo found that, although only $11 \%$ of the 76 physicians in the study had burnout, 74\% showed moderate to high levels of emotional exhaustion, $28 \%$ showed low professional accomplishment and $79 \%$ had moderate to high rates of depersonalization ${ }^{11}$. Immersed in this suffering, medical residents are more susceptible to mental disorders such as anxiety, depression, substance abuse and suicidal thoughts ${ }^{12-14}$. At the same time, the consequences go beyond the resident, affecting the patients, who can suffer from preventable medical errors and also from cold and impersonal treatment ${ }^{12,13}$.

Based on this perspective, this study aimed to describe and analyze the prevalence of burnout in resident physicians linked to a Teaching Hospital with a medical residency program accredited by the National Medical Residency Council since 1977. Furthermore, it sought to verify whether there is any correlation of the presence of burnout with sociodemographic and socioeconomic data. At the end of the study, it was possible to reflect on what this represents for medical training and how we can contribute to improving it.

\section{METHOD}

\section{Sample and data collection}

One hundred and two of 221 medical residents participated in this analytical, cross-sectional and quantitative study, originated from all areas offered by the medical residency program, and enrolled during the period of August to December 2019. The residents were invited to carry out the survey in person and at separate times, after their weekly specialty meetings, at the same time they were informed about the time to complete the questionnaire, lasting 15 minutes, the anonymous and voluntary nature of the survey, as well as oriented about the signature of the Free and Informed Consent Form.

\section{Instruments}

The following instruments were used: a) sociodemographic questionnaire developed by the researchers for this study, which assesses the following variables: age, number of children, gender, marital status, year of residency, specialty and number of jobs; b) the Brazilian Economic Classification Criteria (CCEB, Classificação Econômica Brasil) of ABEP (Brazilian Association of Research 
Companies) socioeconomic questionnaire. This economic segmentation instrument consists of 15 items and uses the survey of household characteristics (presence and quantity of some household comfort items, the origin of the water used in the household, the presence of asphalt on the street where the household is located and the level of education of the head(s) of the family. The criterion assigns points according to each characteristic and adds up these points to determine the individual's economic class and average monthly income in Brazilian reais, and the higher the number of points that constitute the sum, the higher the class. The classification according to the score is: 45-100 points, economic class A, with an average income of $R \$ 25,554.33$; 38-44 points, economic class B1, with an average income of $\mathrm{R} \$ 11,279.14$; 29-37 points, economic class B2, with $\mathrm{R} \$ 5,641.64 ; 23-28$ points, economic class $\mathrm{C} 1$, with $\mathrm{R} \$ 3,085.48$; 17-22 points, economic class $\mathrm{C} 2$, with $\mathrm{R} \$ 1,748.59$; and $0-16$ points, class $D-E$, with an average monthly income of $R \$ 719.81$. Finally, the questionnaire: c) Maslach Burnout Inventory (MBI) version HSS (Human Services Survey). The MBI is a self-administered questionnaire, with a five-point Likert-type scale in which zero is scored for never, one for a few times a year, two for a few times a month, three for a few times a week and four for daily. The instrument, validated in Brazil by Lautert (1995) ${ }^{15}$, Tamayo $(1997)^{16}$, Benevides-Pereira (2001) ${ }^{17}$ and Carlotto and Câmara $(2007)^{18}$, comprises 22 items distributed into three subscales: 9 questions about emotional exhaustion, 8 questions about professional accomplishment and 5 questions about depersonalization. The analysis of the questionnaire allows identifying the values of three variables for each individual, which, according to the obtained score, characterize the Burnout Syndrome. Meeting only one criterion is not considered a risk situation, nor the absence of burnout, which is characterized by values above those reported for EE and DE and below those reported for PA.

\section{Statistical analysis}

To describe the sample profile, frequency tables of categorical variables (gender, marital status, year of residency, specialty, has another job) were created using absolute frequency values ( $n$ ) and percentage (\%), and descriptive statistics of numerical variables (age, average income, number of children), with mean values, standard deviation, minimum and maximum values, median and quartiles.

The chi-square or Fisher's exact tests were used to compare categorical variables in the burnout syndrome, whereas the Mann-Whitney test was used to compare the numerical variables in the burnout syndrome.

Spearman's correlation coefficient was used to analyze the relationship between numerical variables and burnout scores.

The significance level adopted for the statistical tests was $5 \%$, that is, $\mathbf{P}<\mathbf{0 . 0 5}$.

Cronbach's alpha coefficient was used to analyze the internal consistency of the Burnout Syndrome scale (MBI). Alpha values $>0.60$ indicate good internal consistency, which was verified for the three domains and the total of the scale (alpha=0.880).

The SAS System for Windows (Statistical Analysis System), version 9.2 (SAS Institute Inc, 2002-2008, Cary, NC, USA) was used for the statistical analysis.

\section{RESULTS}

The total number of respondents comprised 102 medical residents, of a group of 221 medical residents enrolled in the year 2019. The group of respondents had a simple mean age of 28.18 years. Of these, there was a higher frequency of females (60.78\%); single individuals (83.33\%); without children (96.08\%); those who had another job (69.61\%); and average income of $\mathrm{R} \$ 5,363.19$ per month (50.98\%).

Most residents were from the clinical area (27.45\%), followed by the surgical area (22.55\%). Residents of orthopedics accounted for $15.69 \%$ of the sample, followed by residents of pediatrics (13.73\%), gynecology and obstetrics (11.76\%), psychiatry (4.90\%), and others (3.92\%) .

Values above the mean for EE and DE and below the mean for PA were established as burnout syndrome. The means of the subscales are shown in Table 1.

The levels of emotional exhaustion, depersonalization and personal accomplishment are shown in Table 2, in which $50.98 \%$ of the sample had a high level of (EE), $50 \%$ had a high level of (DP) and $42.16 \%$ had a low level of (PA). In the sample, $21.57 \%$ had a high level of burnout and $76.74 \%$ had a high level in at least one of the three evaluated dimensions.

Table 3 shows the percentage of high level of each burnout component distributed according to the different demographic variables of the study and the results of inferential statistical tests.

Table 1. Distribution of medical residents according to the Maslach Burnout Inventory means.

\begin{tabular}{lcccc}
\hline \multicolumn{1}{c}{ Subscales } & Mean & SD $^{*}$ & Min. & Max. \\
\hline Emotional exhaustion & 20.78 & 7.22 & 3 & 36 \\
Depersonalization & 6.52 & 3.75 & 0 & 15 \\
$\begin{array}{l}\text { Professional } \\
\text { accomplishment }\end{array}$ & 21.62 & 4.76 & 8 & 32 \\
\hline
\end{tabular}

* SD: Standard Deviation.

Source: Created by the Authors. 
Table 2. Dimensions of medical residents regarding the isolated dimensions of the MBI and burnout.

\begin{tabular}{|c|c|c|c|c|c|c|}
\hline & \multicolumn{2}{|c|}{$\mathrm{EE}$} & \multicolumn{2}{|c|}{$\mathrm{DE}$} & \multicolumn{2}{|c|}{ PA } \\
\hline & $\%$ & Frequency & $\%$ & Frequency & $\%$ & Frequency \\
\hline Low level & 49.02 & 50 & 50 & 51 & 42.16 & 43 \\
\hline \multirow[t]{2}{*}{ High level } & 50.98 & 52 & 50 & 51 & 57.84 & 59 \\
\hline & & & & & $\%$ & Frequency \\
\hline \multicolumn{3}{|c|}{ Burnout syndrome } & & & 21.57 & 22 \\
\hline \multicolumn{3}{|c|}{ High level in at least one index domain } & & & 76.47 & 78 \\
\hline
\end{tabular}

Source: Created by the Authors.

Table 3. Relationship between burnout frequency and each of its dimensions with socio-occupational characteristics of the sample.

\begin{tabular}{|c|c|c|c|c|c|c|c|c|c|c|c|c|c|c|}
\hline \multirow{2}{*}{ Characteristic } & \multicolumn{2}{|c|}{ Total responses } & \multicolumn{3}{|c|}{$\mathrm{EE}$} & \multicolumn{3}{|c|}{$\mathrm{DE}$} & \multicolumn{3}{|c|}{ RPA* $^{*}$} & \multicolumn{3}{|c|}{ Burnout } \\
\hline & $\mathbf{N}$ & (\%) & $\mathbf{N}$ & (\%) & $P$ value & $\mathrm{N}$ & (\%) & P value & $\mathrm{N}$ & (\%) & $P$ value & $\mathbf{N}$ & (\%) & $P$ value \\
\hline \multicolumn{15}{|l|}{ Marital status } \\
\hline Single & 85 & $83.33 \%$ & 41 & $47.67 \%$ & $P=0.215$ & 40 & $46.51 \%$ & $P=0.184$ & 34 & $39.53 \%$ & $P=0.324$ & 16 & $18.60 \%$ & $P=0.193$ \\
\hline Married & 17 & $16.67 \%$ & 11 & $61.11 \%$ & & 11 & $61.11 \%$ & & 9 & $50 \%$ & & 6 & $33.33 \%$ & \\
\hline \multicolumn{15}{|l|}{ Gender } \\
\hline Male & 40 & $39.21 \%$ & 18 & $45 \%$ & $P=0.332$ & 24 & $60 \%$ & $P=0.105$ & 18 & $45 \%$ & $P=0.641$ & 9 & $22.50 \%$ & $P=0.854$ \\
\hline Female & 62 & $60.78 \%$ & 34 & 54.83 & & 27 & 43.54 & & 25 & $40.32 \%$ & & 13 & $20.96 \%$ & \\
\hline \multicolumn{15}{|l|}{ Year of residency } \\
\hline R1 & 35 & $34.31 \%$ & 15 & $42.85 \%$ & $P=0.770$ & 13 & $37.14 \%$ & $P=0.188$ & 12 & $34.28 \%$ & $P=0.683$ & 4 & $11.42 \%$ & $\mathrm{P}=0.385$ \\
\hline R2 & 34 & $33.33 \%$ & 17 & $50 \%$ & & 20 & $58.82 \%$ & & 14 & $41.17 \%$ & & 8 & $23.52 \%$ & \\
\hline R3 & 19 & $18.62 \%$ & 11 & $57.89 \%$ & & 9 & $47.36 \%$ & & 9 & $47.36 \%$ & & 6 & $31.57 \%$ & \\
\hline R4 & 7 & $6.86 \%$ & 4 & $57.14 \%$ & & 4 & $57.14 \%$ & & 4 & $57.14 \%$ & & 2 & $28.57 \%$ & \\
\hline R5 & 6 & $5.88 \%$ & 4 & $66.66 \%$ & & 5 & $83.33 \%$ & & 3 & $50.00 \%$ & & 2 & $33.33 \%$ & \\
\hline R6 & 1 & $0.98 \%$ & 1 & $100 \%$ & & 0 & $0 \%$ & & 1 & $100.00 \%$ & & 0 & $0.00 \%$ & \\
\hline \multicolumn{15}{|c|}{ Area of specialization in medical residency } \\
\hline Surgical Areas & 23 & $22.54 \%$ & 16 & $69.56 \%$ & $P=0.254$ & 18 & $78.26 \%$ & $P=0.013$ & 11 & $47.82 \%$ & $P=0.061$ & 8 & $34.78 \%$ & $P=0.474$ \\
\hline Clinical areas & 28 & $27.45 \%$ & 16 & $57.14 \%$ & & 12 & $42.85 \%$ & & 16 & $57.14 \%$ & & 8 & $28.57 \%$ & \\
\hline Gynecology & 12 & $11.76 \%$ & 5 & $41.66 \%$ & & 7 & $58.33 \%$ & & 3 & $25.00 \%$ & & 2 & $16.66 \%$ & \\
\hline Pediatrics & 14 & $13.72 \%$ & 6 & $42.85 \%$ & & 4 & $28.57 \%$ & & 4 & $28.57 \%$ & & 1 & $7.14 \%$ & \\
\hline Psychiatry & 5 & $4.90 \%$ & 1 & $2 \%$ & & 1 & $2 \%$ & & 0 & $0.00 \%$ & & 0 & $0.00 \%$ & \\
\hline Orthopedics & 16 & $15.68 \%$ & 6 & $37.50 \%$ & & 8 & $50 \%$ & & 9 & $56.25 \%$ & & 3 & $18.75 \%$ & \\
\hline Others & 4 & $3.92 \%$ & 2 & $50 \%$ & & 1 & $25 \%$ & & 0 & $0.00 \%$ & & 0 & $0.00 \%$ & \\
\hline \multicolumn{15}{|l|}{ Has another job } \\
\hline Yes & 71 & $69.60 \%$ & 38 & $53.52 \%$ & $P=0.437$ & 38 & $53.52 \%$ & $P=0.282$ & 27 & $38.02 \%$ & $P=0.201$ & 15 & $21.12 \%$ & $P=0.870$ \\
\hline No & 31 & $30.39 \%$ & 14 & $45.16 \%$ & & 13 & $41.93 \%$ & & 16 & $51.61 \%$ & & 7 & $22.58 \%$ & \\
\hline \multicolumn{15}{|c|}{ Number of children } \\
\hline None & 98 & $96.08 \%$ & 48 & $48.98 \%$ & $\mathrm{P}=0.178$ & 48 & $48.98 \%$ & $P=0.618$ & 40 & $40.81 \%$ & $\mathrm{P}=0.390$ & 20 & $20.40 \%$ & $P=0.203$ \\
\hline 1 Child & 3 & $2.94 \%$ & 3 & $100.00 \%$ & & 2 & $66.66 \%$ & & 2 & $66.66 \%$ & & 1 & $33.33 \%$ & \\
\hline 2 Children & 1 & $0.98 \%$ & 1 & $100.00 \%$ & & 1 & $100.00 \%$ & & 1 & $100.00 \%$ & & 1 & $100.00 \%$ & \\
\hline \multicolumn{15}{|l|}{ Average income } \\
\hline $\mathrm{R} \$ 2,965.69$ & 9 & $8.82 \%$ & 5 & $55.55 \%$ & $P=1.000$ & 4 & $44.44 \%$ & $\mathrm{P}=0.755$ & 7 & $77.77 \%$ & $P=0.006$ & 3 & $33.33 \%$ & $P=0.344$ \\
\hline $\mathrm{R} \$ 5,363.19$ & 52 & $50.98 \%$ & 26 & $50 \%$ & & 25 & $48.07 \%$ & & 17 & $32.69 \%$ & & 8 & $15.38 \%$ & \\
\hline $\mathrm{R} \$ 10,386.52$ & 27 & $26.47 \%$ & 14 & $51.85 \%$ & & 13 & $48.14 \%$ & & 16 & $59.25 \%$ & & 8 & $29.62 \%$ & \\
\hline $\mathrm{R} \$ 23,345.11$ & 14 & $13.72 \%$ & 7 & $50 \%$ & & 9 & $64.28 \%$ & & 3 & $21.42 \%$ & & 3 & $21.42 \%$ & \\
\hline TOTAL & 102 & $100 \%$ & 52 & $50.98 \%$ & & 51 & $50 \%$ & & 43 & $42.15 \%$ & & 22 & $21.57 \%$ & \\
\hline
\end{tabular}

RPA: reduced professional accomplishment.

Source: Created by the Authors. 
Of the 22 respondents who presented values above the mean for EE and DE and below the mean for PA, characterizing the syndrome, 13 were female and 9 male. As a percentage, these values mean that $22.5 \%$ of the men and $20.96 \%$ of the women showed burnout indicators. Men had higher levels of DE (60\%) and lower levels of PA (45\%) than women, (43.54\%) and (40.32\%), respectively. Women showed higher levels of EE (54.83\%) than men (45\%). However, no significant relationships were found between these variables.

No statistically significant differences were found in the relationship between the interviewees' marital status and having burnout or with the frequency of any of the $E E, D E$ and PA subscales. Also, there were no differences in the stratification of the sample by income range, except for a significant $p$ alpha for the dimension of reduced professional accomplishment in those who declared a mean monthly income of $R \$ 2,965$ and $R \$$ 10,386.00 ( $\mathbf{P = 0 . 0 0 6 )}$.

Based on the results, there was a difference in the association between emotional exhaustion and the number of children. The larger the number of children, the higher the $\mathrm{EE}$ value $(\mathbf{P}=\mathbf{0 . 0 4 7})$.

Residents who had another job showed the highest rates of $\mathrm{EE}(53.52 \%)$ and $\mathrm{DE}$ (53.52\%), while residents who did not have another job had lower PA values (51.62\%).

Physicians in the fifth year of residency had the highest percentage of $\mathrm{EE}, \mathrm{DE}$ and burnout syndrome, but no significant relationship was found between these variables. In addition, Graph 1 demonstrates that the overall levels of burnout tend to be higher as the years of residency advance.

When comparing the medical specialties, no significant relationship was found between this variable and burnout levels, although residents in the surgical area showed the highest levels of DE (78.26\%) ( $\mathbf{P}=\mathbf{0 . 0 1 3})$.

The results showed a significant difference between emotional exhaustion for: depersonalization $(\mathbf{P}<\mathbf{0 . 0 0 1})$ and reduced professional accomplishment $(\mathbf{P}=\mathbf{0 . 0 0 1})$ (higher frequency of yes in those with emotional exhaustion), DE score $(\mathbf{P}<\mathbf{0 . 0 0 1})$ (highest values in those with emotional exhaustion)

Graph 1. General levels of exhaustion related to years of residency.

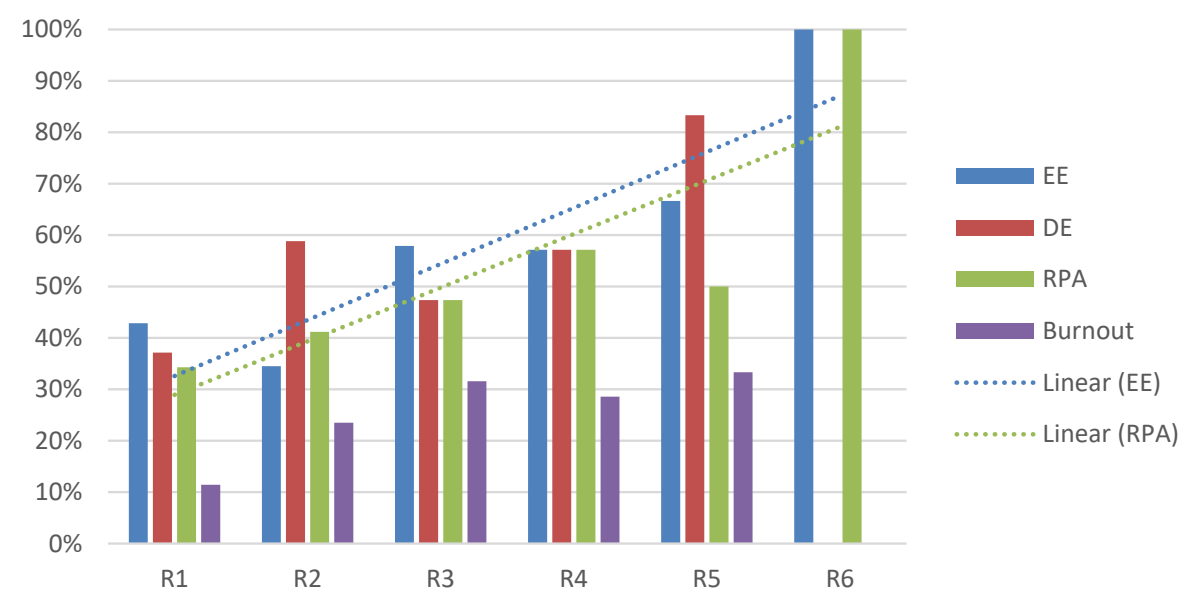

Source: Created by the Authors.

Graph 2. Relationship between the three dimensions of burnout among themselves.

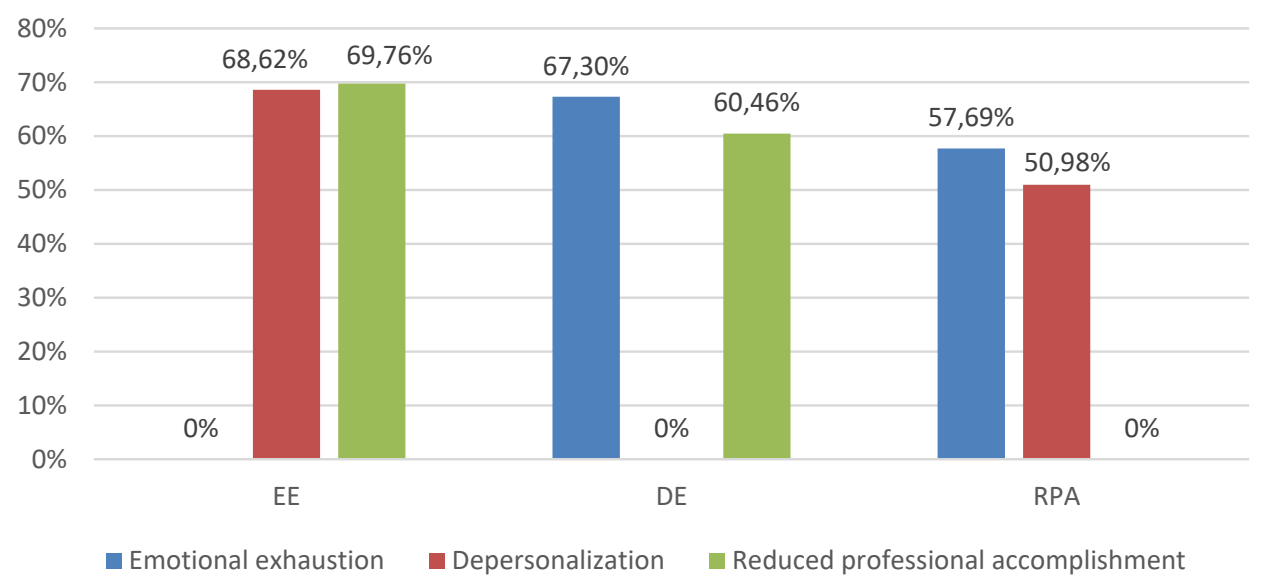

Source: Created by the Authors. 
and PA score $(\mathbf{P}<\mathbf{0 . 0 0 1})$ (lower values in those with emotional exhaustion). There was also a significant difference between depersonalization for: emotional exhaustion $(\mathbf{P}<\mathbf{0 . 0 0 1})$ (higher frequency of yes in those with depersonalization) and EE score $(\mathbf{P}<\mathbf{0 . 0 0 1})$ (higher values in those with depersonalization). Moreover, there was a significant alpha $\mathrm{p}$ between reduced professional accomplishment for: emotional exhaustion $(\mathbf{P}=\mathbf{0 . 0 0 1})$ (higher frequency of yes in those with reduced professional accomplishment) and $\mathrm{EE}(\mathbf{P}<\mathbf{0 . 0 0 1})$ and $\mathrm{DE}$ $(\mathbf{P}=\mathbf{0 . 0 0 5})$ scores (higher values in those with reduced professional accomplishment), see Graph 2.

\section{DISCUSSION}

Medical residency in Brazil, desired by most medical students, is seen as the validation of a dream and the chance of career advancement. However, the challenges that this moment imposes end up affecting those who intend to carry out a specialization aimed at personal, professional and financial accomplishments. Known as the most arduous period in a doctor's life, the residency is surrounded by high demands, long working hours, low pay and a duality between being a doctor, but still living and being treated as a student ${ }^{5-7,19}$. Therefore, the high susceptibility of these professionals to burnout is what justifies this study and many others around the world.

Symptoms of burnout in Medicine can originate from several causes, such as bureaucratic requirements, continually changing work environments, poor hospital management, poor clinical supervision, sensational media reports of medical errors, limited health resources, and a poor balance between work and personal life 20,21 .

In our study, the prevalence of burnout syndrome was $21.56 \%$, with 102 respondents. According to the Federal Council of Medicine (CFM, Conselho Federal de Medicina), in Brazil, $23.1 \%$ of doctors have a high degree of burnout syndrome ${ }^{22}$. In other national publications, the presence of this syndrome varies from $20.8 \%$ to $81.5 \%{ }^{1,19}$. In a global meta-analysis study of 22,778 individuals, an aggregate burnout prevalence of $51 \%$ was identified ${ }^{21}$, whereas, in a Syrian study, the prevalence of burnout in 3,350 residents was $19.3 \%{ }^{23}$.

Therefore, it is inferred that although our study shows results similar to the national average reported by the CFM, when compared to other national and international studies, there is a lot of discrepancy and variation, of approximately $60 \%$, regarding the results. This difference is due to the score variables that define the existence of burnout in the literature. In a publication from the U.K., the presence of the syndrome is defined by the change in the three dimensions (depersonalization, emotional exhaustion and professional accomplishment) ${ }^{24}$, but in a Canadian study, the presence of burnout is defined by the presence of change in only one of the three dimensions ${ }^{25}$. In studies similar to ours, carried out in university hospitals with medical residents ${ }^{1,19,23}$, the criterion for the definition of burnout was the presence of three dimensions, and if only two are present, it is considered a risk situation, as also defined in our research. Therefore, it is necessary to consider whether the research needs to increase the assessed sample, seeking a greater confidence interval, or whether the $\mathrm{MBI}$ instrument is still adequate, since it is dated from the $80 \mathrm{~s}^{3,22}$, aiming to update and standardize what would be the ideal definition of the presence or absence of the disease.

The sample of medical residents assessed in the present study had a majority of female individuals (60.78\%), of which 13 had burnout, representing $20.96 \%$ of the total number of women. Men, on the other hand, were only $39.21 \%$ of the sample, but showed $22.5 \%$ of burnout in the assessed sample. When observing the total number of respondents with criteria for burnout, which totaled 22 individuals, 59.09\% were women, while $40.9 \%$ were men. Therefore, the scenario of a majority of women in the sample in medical teaching centers worldwide is repeated in other studies, with numbers ranging from $56.30 \%$ and $69.3 \%$ of women in Canada ${ }^{12,26}$ and in Porto Alegre, with $58.3 \%$ of women, which shows a sociodemographic change of more than 60 years, with an increase in the number of female medical professionals, which was $23.47 \%{ }^{27}$ in the 1970 s, to $45.6 \%$ of graduated professionals ${ }^{28}$ in 2018 , with an expectation of being the majority in the medical labor market by $2028^{27}$. However, although females seem as the absolute majority, males are still the most affected by burnout, as shown by these national and international studies ${ }^{19,21,23}$. Therefore, it demonstrates that men possibly suffer more from the stressful factors of medical life, such as the residency low salary, high demand from superiors and patients, having many administrative tasks, in addition to working long hours, lack of respect and insufficient compensation, which are added to the role socially attributed to the man as the breadwinner of the house and to be financially successful ${ }^{23,29}$. Despite this, the association between gender and burnout prevalence is not well consolidated and shows discrepancies in other studies, which indicates the possibility of it not being a good demographic indicator for the prevalence of the syndrome $e^{1,19,30}$.

When observing the dimensions of the syndrome in the study, women are the majority regarding emotional exhaustion, with $65.38 \%$, in depersonalization with $52.94 \%$ and in reduced professional accomplishment with 58.14\%. However, in other national studies, females lead emotional exhaustion, while males lead depersonalization ${ }^{1,19}$; however, when analyzing the Syrian study, males lead the three dimensions ${ }^{23}$. The national results are in line with an 
international meta-analysis on burnout and gender, which indicatesahigherprevalence ofemotionalexhaustion reported by women, while men report more depersonalization ${ }^{30}$. Despite this, the fact that the questionnaire application is voluntary, that the sample is predominantly female and that the relationships between gender and the presence of the syndrome show a lot of discrepancy in the world literature, it is not possible to affirm that there is a direct relationship between any of the spectra and gender.

When observing the marital status of the study group, the fact of being married showed to be a possible risk factor, since $35.29 \%$ of these had burnout against $18.82 \%$ of single individuals; moreover, those had higher rates of DE, EE and reduced PA. This is observed in other national publications, in which married residents are at greater risk of developing the syndrome ${ }^{1,19}$. However, when analyzing the spectra in these studies, single individuals showed higher values of depersonalization and professional accomplishment ${ }^{1}$, which appears as the opposite situation in another study ${ }^{19}$. Therefore, it is possible to infer that the need to balance the demands of family and affective relationships with large loads of affective responsibility may be a stressor associated with factors inherent to the medical residency activity, but without excluding the possibility that singles may have risk factors for developing burnout as well.

Considering the issue of the number of children, not having children showed to be a possible protective factor, since, in this group, only $20.4 \%$ had a set of dimensions that characterize burnout, but it was shown to be a possible risk factor for EE and DE, albeit not related to PA. This may be due to the fact that they do not have extra concerns or responsibilities that can be triggering factors for stress, such as family and children, associated with the stressful factors of medical practice. However, no other studies were found for comparison.

The year of residency showed to be a possible risk factor, that is, an increased risk of developing the syndrome is likely with more years of completed residency, with $11.4 \%$ for first-year residents and $33 \%$ for fifth-year residents. This result is similar to another national study ${ }^{19}$ and to the Syrian study ${ }^{23}$, although none of the three studies showed a significant association between year of residency and the presence of the syndrome. This trend may indicate a change in this resident's expectations regarding the profession as the residency progresses, or an increase in the aspirations and responsibilities as the end of the residency approaches and the responsibility for the patient and for the professional future itself increases. In addition to the high expectations and energy when starting the program, which can be lost and give way to burnout symptoms as time goes by. Moreover, the incidence of emotional exhaustion increases as the duration of residency increases, with $42.85 \%$ in the first year and $57.89 \%$ in the third year, as also shown in the study carried out in Porto Alegre and in the Syrian study ${ }^{19}, 23$, albeit without significant relevance between the syndrome and year of residency. There is also a likely increase in the reduction of professional accomplishment as the year of residency increases, contrary to the study carried out in Porto Alegre and the Syrian study ${ }^{19,23}$, which may indicate a change in professional expectations or derealization with the choice made, being $34.28 \%$ in the first year and $47.36 \%$ in the third year.

When analyzing the specialty variable, most participants were from areas known as a prerequisite for going on another residency, which are Internal Medicine (22.55\%) and Surgery $(27.45 \%)$. When observing the presence of spectra and burnout, the surgical area seems to be a possible risk factor for the development of the syndrome (34.78\%), followed by the clinical area (28.57\%), in line with the international metaanalysis, which indicated that there was no difference between the incidence of burnout in the two areas ${ }^{21}$. Despite this, no studies were found with a significant correlation between specialty and greater presence of burnout. Therefore, it is possible to infer a likely relationship between the areas that are configured as a prerequisite with an increased risk for the disease, so that it is possible to question whether the extension of the medical professional training, who is forced to perform two residencies to work in the specialty of their choice, may become a factor that harms their physical and mental health and raises questions about this training model. The chosen specialty, however, does not seem to affect $E E$, but the surgical area shows a higher rate of emotional exhaustion, with $60.86 \%$. It also appears as a risk factor (78.26\%) for the development of depersonalization, while the clinical area (42.85\%) and pediatrics (28.57\%) appear as protective $(\mathbf{P}=\mathbf{0 . 0 1 3})$. In the Syrian study and the one carried out in the state of Minas Gerais, the spectra were no longer present in certain areas, thus not indicating an association ${ }^{1,23}$. Despite this, in the study from Rio Grande do Sul, the surgical area and the pediatrics area appeared as possible protective factors against professional exhaustion and depersonalization ${ }^{19}$. The choice of specialty does not seem to influence professional accomplishment, probably indicating that the area is not important to define this feeling.

When analyzing the income factor, it does not seem to significantly influence the presence or absence of the syndrome, although those with the lowest income, i.e., $\mathrm{R} \$ 2,965.69$, had the highest percentage of burnout (33.33\%), as seen in another Brazilian study ${ }^{19}$, in which $85.5 \%$ of those with an income of less than $\mathrm{R} \$ 3,000.00$ had burnout. However, no publication was found with a significant association between average monthly 
income and the presence of the assessed disease. Therefore, low remuneration may seem to be a risk factor, but without evidence, due to the fact that the financial reality is related to the needs of each individual and the possibility of having another job, besides the residency. Observing the spectra, in our study, the mean income showed a significant association to professional accomplishment, but with variations that do not allow affirming whether more or less income would mean greater or lesser professional accomplishment $(\mathbf{P}=\mathbf{0 . 0 0 6})$, similarly to the study carried out in the city of Porto Alegre, Brazil, which showed variation in professional accomplishment between income values, but without a significant association ${ }^{19}$; that brings a reflection on how much money, which is something objective, can influence the feeling of professional accomplishment, which is something subjective.

In the present study, $69.60 \%$ of respondents had another job, besides the residency. However, having another job did not show indication of a possible risk of or protection against the development of the syndrome. In another national publication, there was also no significant association between burnout and having another job ${ }^{19}$. In an international study, the spectrum of emotional exhaustion was correlated with the high number of worked hours ${ }^{31}$, while in the present study, those who had another job besides the residency and, therefore, worked more hours, did not show more emotional exhaustion than those who only worked the hours required for the residency program. Moreover, having another job appeared as a possible protective factor regarding the reduction of professional accomplishment (38.02\%), similarly to what was observed in the study carried out in Porto Alegre ${ }^{19}$. Therefore, it is understood that having another job can bring more gratification to the resident who, in addition to being a student, can assume the position of doctor at another moment, bringing greater professional satisfaction.

When observing the distribution of respondents between the three dimensions that assess burnout, the population is distributed practically in half in relation to the presence of emotional exhaustion (50.98\%) and depersonalization (50\%). However, when observing the reduced professional accomplishment, $57.84 \%$ said they had achieved professional accomplishment. For Tamayo, emotional exhaustion is the dimension that is easily accepted by professionals, which allows them to understand, express, and admit this feeling ${ }^{1,32}$ more easily. The results are similar in other national studies, ranging from $53 \%-65 \%$ of $\mathrm{EE}, 47.7 \%-61.7 \%$ of $\mathrm{DE}$ and $30 \%$ - $45 \%$ of $P A^{1,19}$, similarly to the Syrian study with $77.9 \%$ of $E E$, $54.6 \%$ of DE and $13.7 \%$ of PA. Therefore, it is possible to infer that despite the high $\mathrm{EE}$ and $\mathrm{DE}$, professional accomplishment can be felt by most residents, even with physical and mental stress, low remuneration and long working hours. Hence, although the other two factors that demonstrate the beginning of a reduction in quality of life are present in most respondents' answers, they still feel as accomplished professionals. This is in agreement with Marshal's definition of reduced professional accomplishment, associating it to the offered structure and the possibility of carrying out their work, which seems to be positive in the residency programs in the country and in the world, including the assessed teaching hospital. Moreover, it is necessary to point out that due to the valorization in the medical society of traditional schools, it is possible to infer that the greater professional accomplishment observed in the study can be partly attributed to the fact that the assessed teaching hospital has offered medical specialization since 1977, being recognized in the medical market.

By analyzing the presence of EE in the DE scenario and vice versa, the result of our research demonstrates a direct relationship between the presence of emotional exhaustion and depersonalization. This result is consistent with the study carried out in the city of Curitiba, state of Prana, Brazil, which interviewed 136 residents and found a high level of emotional exhaustion and depersonalization, with a moderate level of personal accomplishment, as well as other national studies conducted in the cities of Porto Alegre and Uberlândia, as well as international studies carried out in Syria and Canada, who showed similar results $15,19,23,26$. Therefore, it is possible to conclude that ED and EE, in this research, occur simultaneously, thus indicating which individual is at high risk for the development of the disease, with PA being a determinant in the classification or not of each participant within the burnout syndrome, thus highlighting those who should be the object of interventions.

This study has some limitations that need to be mentioned. First, due to the difficulty of having access to residents and the incompatibility of timetables with those of the researchers, some groups were unable to participate in the study. Moreover, during the approaches in clinical meetings, some residents were absent, and therefore were not included in the study. Additionally, some of the participants were already aware of the topic, which may have resulted in a familiarity bias, or due to psychological distress and stress. Finally, some residents were afraid to answer the questions, for fear that the provided information, especially about the external work, would reach the knowledge of their superiors, since the residency is a high dedication program. Consequently, the sample may have suffered some selection bias. Second, the research addresses subjective issues, which despite being validated and acknowledged in the MBI-HSS, can be considered a measurement bias. Third, because it is a cross-sectional study, it does not allow inferring causality, requiring further studies. 
Finally, the sample of 102 residents does not represent the totality of residents of the institution, which shows the need to expand the study to attain better results.

Considering all of the above, it is possible to infer that, despite not being a large number of residents who portray all spectra and diagnostic criteria for burnout syndrome, most study participants showed at least one aspect amongst emotional exhaustion, depersonalization and reduced professional accomplishment, with approximately half of them showing EE and DE. Therefore, it is necessary to point out that they show some level of suffering and that interventions are necessary to prevent the situation from getting worse. Thus, we can suggest better remuneration, so that the financial issue is not a possible factor of suffering, in addition to allowing the feeling of recognition for one's work, and for the weekly hours dedicated to this work. This would also prevent the need to have another job, allowing the individual more free time to invest in themselves and in performing activities that bring relaxation and improve well-being, physical and mental health. Moreover, the institution must lead non-mandatory support groups, with professionals trained to offer psychological support to those who wish it, since the assessed institution had only one support channel for the entire college community (undergraduate students, teachers, employees and residents), and not specific to medical residents and their particularities. It is also necessary to review the peculiarities of the specialties, since the one that repeatedly showed the greatest chance of risk and suffering in this study was the surgical area, which may suggest the existence of characteristics that can put the residents who choose this specialization at risk. In addition, harming the physical and mental health of medical residents indirectly affects the quality of patient treatment ${ }^{33}$ and increases the risk of preventable errors ${ }^{9,12,13}$. Evidence shows prescription errors and reduced quality of medical services due to exhaustion, potentially affecting the interprofessional relationship ${ }^{21,33}$. As a prevention strategy, studies show that 3 changes are recommended to reduce the risk of burnout: modification of the organizational structure; the adequacy between the organization and the physician; and actions at the individual level, through healthy behaviors ${ }^{21,34}$. Therefore, it is concluded that more studies on the subject are required, aiming at a better understanding of the current scenario, its aggravating factors and establishing the best forms of intervention aimed to reduce physical and mental exhaustion of medical residents and improve the quality of care.

\section{CONCLUSION}

The prevalence of Burnout among resident physicians was $21.57 \%$, consistent with the literature. This may indicate that medical residents are being exposed to a multitude of emotions that contribute to high levels of stress and distress.

Moreover, this study showed that there was a significant relationship between the choice of the surgical area by the residents with depersonalization, higher values of emotional exhaustion with a larger number of children, and a direct relationship between the presence of emotional exhaustion, depersonalization and reduced professional accomplishment.

Finally, more studies are required to understand the coping mechanisms aiming to prevent and reduce the effects of Burnout in medical residents. A favorable environment is necessary, in which residents can thrive, attain well-being and build resilience. Achieving these goals will help promote the competence, dedication and professionalism of future physicians during the training process and throughout their careers.

\section{ACKNOWLEDGMENTS}

The authors would like to thank the statistician Helymar Machado for performing the analysis and managing the database.

\section{AUTHORS' CONTRIBUTION}

José Augusto Costa participated in the literature search, data analysis and critical review of the manuscript. Nicoli Abrão Fasanella participated in the literature search, data collection, data analysis and writing of the final version of the manuscript. And the students Beatriz Mendonça Schmitz and Patrick Cavalcanti Siqueira together carried out the literature search, data collection, data analysis and writing of the final version of the manuscript.

\section{CONFLICTS OF INTEREST}

The authors declare no conflicts of interest.

\section{SOURCES OF FUNDING}

This study was funded by the Teaching, Research and Extension Council (CEPE, Conselho de Ensino, Pesquisa e Extensão) Pontifícia Universidade Católica de São Paulo (PUC-SP).

\section{REFERENCES}

1. Lima FD, Buunk AP, Bernadete $M$, Araújo J, Gomide J, Chaves $M$, et al. Síndrome de burnout em residentes da Universidade Federal de Uberlândia - 2004. Rev Bras Educ Med. 2007;31(2):137-46.

2. Mendanha M, Bernardes P, Shiozawa P. Desvendando o burnout: uma análise interdisciplinar da síndrome do esgotamento profissional. São Paulo: LTr; 2018

3. Maslach C, Jackson SE. The measurement of experienced burnout. J Organ Behav. 1981;2(2):99-113.

4. Soares LR, Lopes TMO, Silva MAO, Ribeiro MVA, Almeida Júnior MP, Silva $\mathrm{RA}$, et al. Burnout e pensamentos suicidas em médicos residentes de hospital universitário. Rev Bras Educ Med. 2012;36(1):77-82. 
5. Asaiag PE, Perotta B, Martins MA, Tempski P. Avaliação da qualidade de vida, sonolência diurna e burnout em médicos residentes. Rev Bras Educ Med. 2010;34(3):422-9.

6. Lockley SW, Cronin J, Evans EE, Cade BE, Clark JL, Landrigan C, et al. Effect of reducing interns' weekly work hours on sleep and attentional failures. $\mathrm{N}$ Engl J Med. 2004;351(15):1493-501.

7. Madsen T. Resident burnout. JAMA. 2004;292(23):2880-9.

8. Linzer M, Manwell LB, Mundt M, Williams E, Maguire A, McMurray J, et al. Organizational climate, stress, and error in primary care: the MEMO study. Adv Patient Saf. 2005;1:65-78.

9. Wen J, Cheng Y, Hu X, Yuan P, Hao T, Shi Y. Workload, burnout, and medical mistakes among physicians in China: a cross-sectional study. Biosci Trends. 2016;10(1):27-33.

10. Borges L, Argolo J, Pereira A, Machado E, Silva W. A Síndrome de burnout e os valores organizacionais: um estudo comparativo em hospitais universitários. Psicol Reflex Crit. 2002;15(1):189-200.

11. Magalhães RAC, Glina DMR. Prevalência de burnout em médicos de um hospital público de São Paulo. Saúde, Ética \& Justiça. 2006;11(1-2):29-35.

12. Kealy D, Halli P, Ogrodniczuk JS, Hadjipavlou G. Burnout among Canadian psychiatry residents: a national survey. Can J Psychiatry. 2016;61(11):732-6.

13. Rodrigues H, Cobucci R, Oliveira A, Cabral JV, Medeiros L, Gurgel K, et al. Burnout syndrome among medical residents: a systematic review and meta-analysis. PLoS One. 2018;13(11):1-17.

14. West CP, Dyrbye LN, Erwin PJ, Shanafelt TD. Interventions to prevent and reduce physician burnout: a systematic review and meta-analysis. Lancet. 2016;388(10057):2272-81.

15. Lautert L. $O$ desgaste profissional do enfermeiro [dissertação]. Salamanca: Universidad Pontificia de Salamanca; 1995.

16. Tamayo MR. Relação entre a síndrome de burnout e os valores organizacionais no pessoal de enfermagem de dois serviços públicos [dissertação]. Brasília: Universidade de Brasília; 1997.

17. Benevides-Pereira AMT. MBI - Maslach Burnout Inventory e suas adaptações para o Brasil. Anais da Reunião Anual de Psicologia. Rio de Janeiro: Sociedade Brasileira de Psicologia; 2001.

18. Carlotto MS, Câmara SG. Propriedades psicométricas do Maslach Burnout Inventory em uma amostra multifuncional. Estud Psicol. 2007;24(3):325-32.

19. Bond MMK, de Oliveira MS, Bressan BJ, Bond MMK, da Silva ALFA, Merlo ÁRC. Prevalência de burnout entre médicos residentes de um hospital universitário. Rev Bras Educ Med. 2018;42(3):97-107.
20. Kumar S. Burnout and doctors: prevalence, prevention and intervention. Healthcare. 2016;4(37):1-9.

21. Low ZX, Yeo KA, Sharma VK, Leung GK, McIntyre RS, Guerrero A, et al. Prevalence of burnout in medical and surgical residents: a meta-analysis. Int J Environ Res Public Health. 2019;16(9):1-22.

22. Moreira HA, de Souza KN, Yamaguchi MU. Síndrome de burnout em médicos: uma revisão sistemática. Rev Bras Saúde Ocup. 2018;43(3):1-11.

23. Alhaffar BA, Abbas G, Alhaffar AA. The prevalence of burnout syndrome among resident physicians in Syria. J Occup Med Toxicol. 2019;14(31):1-8.

24. Ramirez AJ, Graham J, Richards MA, Cull A, Gregory WM, Leaning MS, et al. Burnout and psychiatric disorder among cancer clinicians. Br J Cancer. 1995;71(6):1263-9.

25. Grunfeld E, Whelan TJ, Zitzelsberger L, Willan AR, Montesanto B, Evans WK. Cancer care workers in Ontario: prevalence of burnout, job stress and job satisfaction. Can Med Assoc J. 2000;163(2):166-9.

26. Ferguson C, Low G, Shiau G. Resident physician burnout: insights from a Canadian multispecialty survey. Postgrad Med J. 2020;0:1-8.

27. Scheffer M., coordenador. Demografia médica no Brasil. São Paulo: Cremesp; 2013.v. 2.

28. Associação Médica Brasileira. Demografia médica 2018: o perfil do médico brasileiro e a desigualdade no acesso à assistência. Rev Med (Puebla). 2018;1(4):1-35.

29. Mannam S. Are physicians happy with their jobs ? Addressing physician burnout. J Young Investig. 2019;37(1):6-7.

30. Purvanova RK, Muros JP. Gender differences in burnout: a meta-analysis. J Vocat Behav. 2010;77(2):168-85.

31. Gabbe SG, Melville J, Mandel L, Walker E. Burnout in chairs of obstetrics and gynecology: diagnosis, treatment, and prevention. Am J Obstet Gynecol. 2002;186(4):601-12.

32. Tamayo MR. Burnout: implicações das fontes organizacionais de desajuste indivíduo-trabalho em profissionais da enfermagem. Psicol Reflex e Crit. 2009;22(3):474-82.

33. Dewa $C S$, Loong $D$, Bonato $S$, Trojanowski L, Rea M. The relationship between resident burnout and safety-related and acceptability-related quality of healthcare: a systematic literature review. BMC Med Educ. 2017;17(195):1-16.

34. Lee RT, Seo B, Hladkyj S, Lovell BL, Schwartzmann L. Correlates of physician burnout across regions and specialties: a meta-analysis. Hum Resour Health. 2013;11(48):1-16. 